\title{
Keloids and breast fibroadenomas in two black teenage girls
}

\section{Ida Aurélie Lenga Loumingou}

Department of Dermatology, University of Brazzaville Medical Center, Brazzaville, Republic of the Congo

Corresponding author: Dr. Ida Aurélie Lenga Loumingou, E-mail: idalengaloumingou@gmail.com

\begin{abstract}
Discuss the relationship between keloids and mammary fibroadenoma. Two teenage girls aged 15 and 19 had been operated on for breast fibroadenomas. Two years later, they consult for post-operative keloids. They have family's history of diabete or high blood pressure. The oldest have hyperandrogenism. The anamnesis in both cases recovers a contusional trauma of the breast, before the perception of the adenofibroma. Breast fibroadenomas and keloids have some common etiopathogenic characteristics. The combination of these two diseases may be relevant.
\end{abstract}

Key words: Keloid; Fibroadenoma; Breast; Trauma; Teenager

\section{INTRODUCTION}

Keloids are benign tumours of connective tissue that are formed as a result of a loss of substance or an inflammatory skin process and are abnormal in healing [1]. The etiopathogenesis of keloids is unknown [2]. Authors suggest immunological, genetic, hormonal and environmental mechanisms [3] as well as the identification of genetically favourable sites $[2,4]$. Stimulation of interleukins and dysregulation of growth hormone would predispose patients with keloids to vascular, metabolic and tumor pathologies [3-5]. Tumours associated with keloids are traditionally uterine fibroids [5]. It is this context of co-morbidity with uterine fibroids that has sparked interest in seeking a link between keloids and fibroadenomas in adolescent girls.

\section{CASE REPORT}

\section{Case 1}

A 15-year-old girl, referred by the gynaecology department for a keloid scar on her left breast. The scar was caused by the removal of a breast fibroadenoma 2 years earlier. The scar is quadrangular, $3.5 \mathrm{~cm} \times 2.5 \mathrm{~cm}$, hyperchromic, hard, bumpy and pruritic. The patient is in good general condition, the body mass index is $21 \mathrm{~kg} / \mathrm{m}^{2}$.
In the history there is a notion of contusional trauma prior to adenofibroma, a notion of hypertension in the mother, a regular menstrual cycle, menarche at 12 years of age, nulligest, she does not take estroprogestins.

\section{Case 2}

A 19-year-old girl consulted for a left breast keloid. The history of the scar would go back three years. The patient had undergone an excision of left breast fibroadenoma documented by pathology anatomy. The scar is hard, polypoid, measures $3 \mathrm{~cm} \times 2 \mathrm{~cm}$ (Fig. 1) it is itchy and sensitive. The patient is in good general condition with a body mass index of $18 \mathrm{~kg} / \mathrm{m}^{2}$. She has documented hirsutism and functional ovarian cysts documented contemporary with hyperandrogenism. The history includes breast contusion, maternal diabetes. Menarche at 12 years old, she is nulligest, does not take estroprogestins.

\section{DISCUSSION}

These observations concern non-obese, nulligest adolescents whose particularity is the hormonal imbalance caused by puberty. Breast fibroadenoma is a benign fibroepithelial tumor characterized by the proliferation of glandular and stromal cells $[6,7]$. It is

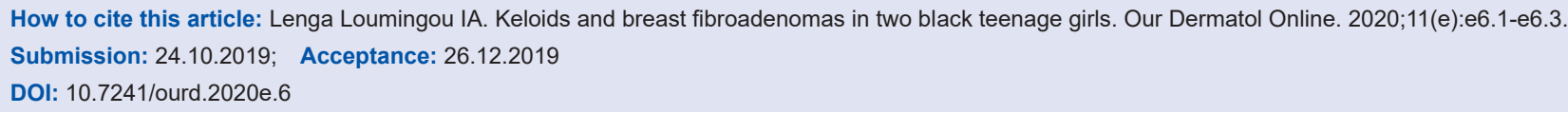




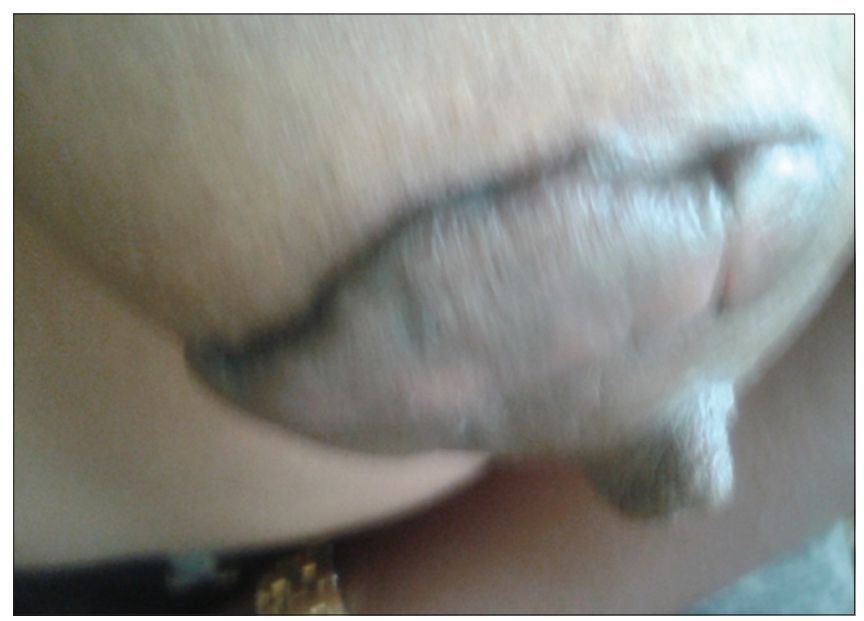

Figure 1: Keloids of breast after fibroadenoma ablation.

best described in Negroid or Mongoloid women aged 10 to 25 years $[8,9]$. Their pathogenesis is unknown; they are influenced by genetic and hormonal factors $[10,11]$. Keloid scars are benign connective tissue tumours that are formed from scarring anomalies [1]. Keloids are post-injury or more rarely spontaneous [4].

Genetic factors associated with endogenous and exogenous factors play a role in the formation of keloids $[3,4,12]$. Keloids can be localized or disseminated, they can be associated with high blood pressure, diabetes and uterine fibroids $[5,13,14]$.

The association of keloids with uterine fibroids is proven but their association is not described with mammary fibroadenomas.

The arguments in favors of a relevant association are:

- The mammary gland has an ectodermal origin [15], it can be assumed that structures of the same embryonic origin share the same pathologies.

- The fibroblastic nature of the two pathologies $[4,7]$.

- The disproportionate frequency of the two diseases in black populations $[8,16]$.

- The hormone dependence of these two pathologies $[6,10,13]$, the abundance of growth hormone receptors [10]. The abundance of giant juvenile forms [17-19].

The arguments for a fortuitous association:

- The relative banality for black subjects to make keloids $[8,16]$.

- The existence of adenofibromas in Caucasian women [10] whose extreme rarity to develop keloids is known [12].
Two questions are worth asking:

- The role of age: Adenofibroma develops more frequently in adolescent girls [20]. We noted a case of adenofibroma in a 2-year-old girl [18], as well as giant forms in teenage girls [19]. Keloids have a higher average age of onset but their onset in adolescence is not uncommon [16].

- The role of trauma: Trauma is a circumstance found before symptoms. Its role in the pathogenesis of fibroadenoma can be discussed, with keloid being chronologically attributed to excisional surgery.

\section{CONCLUSION}

Several endogenous factors suggest that the association of keloids and breast fibroadenomas is relevant. This work should be further developed. It seems appropriate to prevent the appearance of keloids in breast surgery in general but particularly in adolescent women with fibroadenoma.

\section{Consent}

The examination of the patient was conducted according to the Declaration of Helsinki principles.

The authors certify that they have obtained all appropriate patient consent forms. In the form the patient(s) has/have given his/her/their consent for his/her/their images and other clinical information to be reported in the journal. The patients understand that their names and initials will not be published and due efforts will be made to conceal their identity, but anonymity cannot be guaranteed.

\section{REFERENCES}

1. Berman B, Maderal A, Raphael B. Keloids and Hypertrophic Scars: Pathophysiology, Classification and Treatment. Dermatol Surg. 2017;43 Suppl 1:S3-S18.

2. Keeling BH, Taylor BR. Cheloids and non-diabetic kidney disease: Similarities of the APOL1-MYH9 haplotype as a possible genetic link. Assumptions Med. 2013;81:908-10.

3. Mari W, Alsabri SG, Tabal N, Younes S, Sherif A, Simman R. Novel Insights on Understanding of Keloid Scar. J Am Coll Clin Wound Spec. 2015;7:1-7.

4. Ogawa R. Keloid and hypertrophic scars are the result of chronic inflammation in the reticular dermis. Int J Mol Sci. 2017;18:pii:E606.

5. Carrino DA, Massiano S, Baker NN WWH, Capla AI. Proteoglycans of uterine fibroids and keloid scars: Similarities in their proteoglycan composition. Biochem J. 2012;443:361-8.

6. Vukovic L, Crnogora CN, Panjkovic M, Miladinovic Bozaric A, Filipovic A, Matic S, et al. Comparaison of cytological categories atypical(C3) and suspected(C4) with histological diagnosis of breast lesions. J Buon. 2018;23:366-71.

7. Jung J, Kang E, Chae SM, Kim H, Park SY, Yun B, et al. 


\section{www.odermatol.com}

Development of a management algorithm for the diagnosis of cellular fibroepithelial lesions from core needle biopsies. Int J Surg Pathol. 2018;26:684-92.

8. Gueye KMS, Gueye M, Coulibaly TM, Mahtouk D, Moreau JC. Benign breast tumours in the senology unit of the Aristide Le Dantec University Hospital Centre in Dakar (Senegal). Pan Afr Med J. 2017;27:251.

9. Woodwork- Lacroix M, Lippa N, Bullier B. Breast pathology of the adolescent girl and the young girl. Rep Med Gynecol Endocrinol. 2013;15:387-94.

10. Boisserie Lacroix M, Lebier-Michel N, Cavagni P, Bentolila J, Laumonier $\mathrm{H}$, Bouzgarou $\mathrm{M}$, et al. Hormones and breast density. J Radiol. 2008;89:1196-203.

11. Giannos A, Stavrou S, Gkali C, Chra E, Marinopoulos S, Chalazonitis A, et al. A prepubertal giant juvenile fibroadenomas in a 12-year-old girl: Case report and brief literature review. Int J Surg Case Rep. 2017;41:427-30.

12. Martinet L. The keloid scar. Retrospective study over 15 years. Thesis. University of Nantes. September 2007.

13. Huguier V, Favot L. Study of the involvement of oncostatin M in the pathophysiology of hypertrophic and keloid scars. Ann Dermatol Venereol. 2015;6-7:287.

14. Ogawa R. High blood pressure can influence the results of clinical trials for the treatment of scars and keloids. Plast Reconstruct Surg. 2013;132:1074e-5e.

15. Larsen WJ. Human embryology. Amazon Edition 1996.

16. Kibadi K, Muhota DK, Mudimisi FN, Mufasoni SM, Mukensi YMW, Mudiani JK. Chéloïdes: epidemiological aspects and reasons for refusing surgical treatment in Kinshasa (Democratic Republic of Congo). Med Santé Trop. 2012;22:55.

17. Lee M, Soltanian TH. Breast fibroadenomas in adolescents: current perspectives. Adolesc Health Med Ther. 2015;6:159-63.

18. Woodard S, Schetter S, Millington K. Diagnosis and imaging characteristics of a juvenile fibroadenoma in a 2-year-old patient: a case report. Radiol Case Rep. 2017;13:6-10.

19. Jategaonkar PA, Jetegaonkar SP, Yadav SP. Super-Giant Juvenile Breast Fibroadenoma: World's First Case. J Coll Physicians Surg Pak. 2018;28:257-8.

20. Huang IC, Li PC, Ding DC. Recurrent juvenile fibroadenoma of the breast in an adolescent: A case report. Medicine (Baltimore). 2018;97:e10765.

Copyright by Ida Aurélie Lenga Loumingou. This is an open-access article distributed under the terms of the Creative Commons Attribution License, which permits unrestricted use, distribution, and reproduction in any medium, provided the original author and source are credited.

Source of Support: Nil, Conflict of Interest: None declared. 